\title{
Vertebrate pest management: research for science-based solutions
}

Vertebrate species are diverse and widespread in Europe. They are vital components of aquatic and terrestrial ecosystems, where they participate in manifold interactions. Vertebrates are important for ecosystem integrity, function and services. Some are resources for humans (hunting) and some are valued because of their appealing nature (iconic species, bird watching). However, there are species that can pose considerable problems to humans because of their role in the transmission of zoonotic diseases, (e.g. hantavirus infection, tularaemia) or livestock disease (e.g. leptospirosis). Due to competition with native fauna and livestock, some species have also had adverse effects on native flora, pre-harvest crop damage, and have caused damage to stored produce and infrastructure.

Problem species - or, more often, problematic overabundant populations of particular vertebrate species - require human intervention to minimise adverse effects. In the case of invasive alien species, European regulation requires eradication or control of the most harmful invasive species. ${ }^{1}$ The possible problems and management approaches are as diverse as vertebrate (pest) species are. ${ }^{2}$ Care needs to be taken so that management action is suitable for all interest groups affected. This is one of the major challenges in vertebrate management and requires sound knowledge of the system to be navigated. Awareness of the potential consequences of management for target, and non-target, populations including environmental, social, ecological, and economical aspects is another key challenge for those involved.

This In-Focus section of Pest Management Science is dedicated to science-based solutions in vertebrate pest management in several taxa and across several continents. The 13 papers in the In-Focus section are drawn from contributions to the $10^{\text {th }}$ European Vertebrate Pest Management Conference, held in September 2015 in Seville, Spain, which was attended by 
182 participants from 34 countries. Topics covered included: biological control of rodent pests by promoting increased raptor predation pressure, urban pest management, control methods and alternatives, agricultural and silvicultural pest management, ecologically based pest management, invasive vertebrates, zoonoses and parasites, and the consequences of control for non-target species. Summaries of all conference abstracts are available at the conference website www.evpmc.org. They clearly demonstrate the science-based adaptation of pest management science in a changing world, looking towards integrating multiple management approaches.

Three contributions cover the topic of how to deal with invasive bird species. Feral pigeons (Columba livia) are an important risk for human health, and a nuisance in building conservation in many cities. Senar et al. showed how educating the public on reducing the food availability to birds resulted in a $40 \%$ reduction in the population size of pigeons. ${ }^{3}$ The common myna (Acridotheres tristis) is a serious threat to the conservation of native endemic avifauna in many islands. Eradication of common myna from small islands is possible but requires a combination of different control methods. ${ }^{4}$ As with the feral pigeons, food shortage may greatly facilitate the control/eradication of the species. A third study describes the quick growth of monk parakeet populations (Myiopsitta monachus) in Israel. ${ }^{5}$ Since 1995 the population has exponentially increased in size, and distribution, in urban and agricultural areas. The authors highlight the potential damage to agriculture and the need to initiate eradication campaigns as soon as possible.

Aside from birds there are also several mammalian species that can interfere with human interests. Rodents are an important threat for public health, native wildlife, and crops in many countries. A survey of Norway rats (Rattus norvegicus) in five European countries found Comentario [j2]: Left unchanged as this is the species name. Leptospira and Rickettsia spp. both as separate, and as co-infections, especially in adult rats 
from rural habitats. ${ }^{6}$ Grey squirrels (Sciurus carolinensis) endanger native red squirrels (Sciurus vulgaris), however, grey squirrels are aesthetically appealing to the general public, adding a social dimension to the management of this species. Through a Bayesian decision network mode, La Morgia et al. ${ }^{7}$ identified the priority areas for population control and concluded that citizen attitude towards the project significantly modifies the optimal strategy of control. Understanding habitat use can greatly help to improve control programs, increasing efficiency and reducing cost. This is also the case in invasive brushtail possums (Trichosurus vulpecula) in New Zealand, where habitat use and home range size is varied in response to population abundance. ${ }^{8}$ When new invasive species appear, rapid response is recommended as the best strategy to reduce the environmental, financial, and welfare cost of eradication/control programs. Of the large-scale alien mammal removal programs conducted in northern Europe, reviewed by Robertson et al., ${ }^{9} 80 \%$ were successful.

Worldwide, one of the main tools for rodent management are anticoagulant rodenticides. ${ }^{10}$ However, there are disadvantages in using these compounds including environmental persistence and resistance. The former was demonstrated by Martínez-Padilla et al. ${ }^{11}$ who revealed the presence of residues of the common anticoagulant active ingredient, bromadiolone, in nestlings of common kestrels (Falco tinnunculus). The latter was validated by Goulois et al. ${ }^{12}$ in house mice (Mus musculus), where anticoagulant efficiency is severely hampered for some anticoagulant compounds by a introgressed mutation acquired from the Algerian mouse (Mus spretus). An alternative to the use of rodenticidal bait, based on an anticoagulant compound, may be the application of a mix of an anticoagulant active ingredient with other compounds such as cholecalciferol (vitamin $\mathrm{D}_{3}$ ), which seems to be sufficiently effective in rodenticide resistant Norway rats. ${ }^{13}$ 
Some of the most obvious rodent damage is caused pre-harvest in agriculture and forestry and in storage facilities. Rodent damage to rice in Myanmar occurs pre-harvest when Bandicota species remove rice grains from the fields and store them in their burrows, with additional damage being caused by Rattus species that consume rice in storage facilities. ${ }^{14}$ The rice eaten by rodents is equivalent to the amount needed to feed a household in Myanmar for up to four months, which can severely affect food security. ${ }^{14}$ Rodent damage in German forestry is related to outbreaks of common Microtus and Myodes species, indicating density dependent damage patterns. ${ }^{15}$ Time-series analyses show that outbreaks occur largely synchronous in both species, most likely driven by mast of beech trees the year before the outbreak. ${ }^{15}$ Van Loon et al. used historical information about trap success and trap efforts to assess the effectiveness of muskrat (Ondatra zibethicus) removal in the Netherlands. ${ }^{16}$ They identified effort thresholds required to make invasive muskrats decline, which will guide future management approaches.

The work presented at the $10^{\text {th }}$ European Vertebrate Pest Management Conference demonstrates that the scientific community strives to create, and use, robust scientific data, to develop and test suitable vertebrate pest management approaches. This includes a better understanding of invasion processes, patterns, the species implicated, and management options. Previous information about the effect of predators, in the cyclic population dynamics, of some rodent species, provides the opportunity to design systematic and robust experiments to identify potential application in pest management. New molecular approaches presented at this conference have provided details about the mechanism of resistance to rodenticides in commensal rodent species. Also, the overlap between pest management and conservation has become evident. In many cases, the knowledge and tools developed to control pests have been important to promote conservation measures. The contributions clearly show that scientific 
findings can further vertebrate pest management regarding effectiveness, conservation, animal

welfare, and public opinion.

1. European Union Regulation (EU) No 1143/2014 of the European Parliament and of the Council of 22 October 2014 on the prevention and management of the introduction and spread of invasive alien species. (2014).

2. Huitu $\mathrm{O}$ and Laaksonen $\mathrm{T}$, Vertebrate pest management: diverse solutions for diverse problems. Pest Management Science; 71(2): 165-165 DOI Electronic Resource Number (2015).

3. Senar JC, Montalvo T, Pascual J and Peracho V, Reducing the availability of food to control feral pigeons: changes in population size and composition. Pest Management Science 2016).

4. Feare CJ, van der Woude J, Greenwell P, Edwards HA, Taylor JA, Larose CS, Ahlen PA, West J, Chadwick W and Pandey S, Eradication of common mynas Acridotheres tristis from Denis Island, Seychelles. Pest Management Science (2016).

5. Postigo JL, Shwartz A, Strubbe D and Muñoz AR, Unrelenting spread of the alien monk parakeet Myiopsitta monachus in Israel. Is it time to sound the alarm? Pest Management Science (2016).

6. Heuser E, Fischer S, Ryll R, Mayer-Scholl A, Hoffmann D, Spahr C, Imholt C, Alfa DM, Fröhlich A and Lüschow D, Survey for zoonotic pathogens in Norway rat populations from Europe. Pest Management Science (2016).

7. La Morgia V, Paoloni D and Genovesi P, Eradicating the grey squirrel Sciurus carolinensis from urban areas: an innovative decision-making approach based on lessons learnt in Italy. Pest Management Science (2016).

8. Rouco C, Norbury GL and Anderson DP, Movements and habitat preferences of pests help to improve population control: the case of common brushtail possums in a New Zealand dryland ecosystem. Pest Management Science (2016).

9. Robertson PA, Adriaens T, Lambin X, Mill A, Roy S, Shuttleworth CM and Sutton-Croft $\mathrm{M}$, The large-scale removal of mammalian invasive alien species in Northern Europe. Pest Management Science (2016).

10. Jacob $\mathrm{J}$ and Buckle A. Use of anticoagulant rodenticides in different applications around the world. In Impact of Anticoagulant Rodenticides on Non-Target Wildlife, ed. by van den Brink N, Elliott J, Shore R and Rattner B (2016).

11. Martínez-Padilla J, López-Idiáquez D, López-Perea JJ, Mateo R, Paz A and Viñuela J, A negative association between bromadiolone exposure and nestling body condition in common kestrels. Pest Management Science (2016).

12. Goulois J, Hascoët C, Dorani K, Besse S, Legros L, Benoit E and Lattard V, Study of the efficiency of anticoagulant rodenticides to control Mus musculus domesticus introgressed with Mus spretus Vkorc1. Pest Management Science (2016).

13. Endepols S, Klemann N, Richter D and Matuschka FR, The potential of coumatetralyl enhanced by cholecalciferol in the control of anticoagulant-resistant Norway rats (Rattus norvegicus). Pest Management Science (2016).

14. Htwe NM, Singleton GR and Maw PP, Post-harvest impacts of rodents in Myanmar; how much rice do they eat and damage? Pest Management Science 2016).

15. Imholt $C$, Reil D, Plasil $P$, Rödiger $K$ and Jacob J, Long-term population patterns of rodents and associated damage in German forestry. Pest Management Science DOI 10.1002/ps.4325 (2016). 
16. van Loon EE, Bos D, van Hellenberg Hubar CJ and Ydenberg RC, A historical perspective on the effects of trapping and controlling the muskrat (Ondatra zibethicus) in the Netherlands. Pest Management Science (2016).

\section{Jordi Figuerola}

Department of Wetland Ecology, Estación Biológica Doñana, Sevilla, Spain

CIBER Epidemiología y Salud Pública (CIBERESP), Spain

Juan F. Beltrán

Departamento de Zoología, Universidad de Sevilla, Sevilla, Spain

Jens Jacob

Julius Kühn-Institute, Federal Research Centre for Cultivated Plants, Institute for Plant Protection in Horticulture and Forests, Vertebrate Research, Münster, Germany 